\title{
Digital Food Marketing to Young People: A Substantial Public Health Challenge
}

\author{
Emma Boyland $^{a}$ David Thivel $^{b}$ Artur Mazur $^{c}$ Susanne Ring-Dimitriou ${ }^{d}$ \\ Marie-Laure Frelut ${ }^{\mathrm{e}}$ Daniel Weghuber ${ }^{f}$ On behalf of the European \\ Childhood Obesity Group
}

${ }^{a}$ Department of Psychological Sciences, University of Liverpool, Liverpool, UK; ${ }^{\text {b }}$ Laboratory of the Metabolic Adaptations to Exercise under Physiological and Pathological Conditions (AME2P), Clermont Auvergne University, Clermont-Ferrand, France; ${ }^{C}$ Faculty of Medical, University of Rzeszów, Rzeszów, Poland; ${ }^{\mathrm{d}}$ Department of Sport and

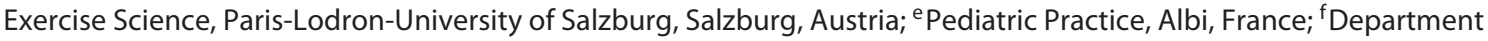
of Pediatrics, Paracelsus Medical University, Salzburg, Austria

Prevention of childhood obesity is an international public health priority, given the significant impact of excess weight on acute and chronic diseases, general health, development and well-being [1]. Given the limited effect of interventions at the individual level [2], more comprehensive measures are needed in a "joinedup, whole systems approach" [3] in line with the EU Action Plan [4].

One area that has attracted considerable attention as a modifiable risk factor for unhealthy diets and weight gain is digital marketing. The proliferation of digital food and beverage marketing has led to concerns about the influence of this type of exposure on the health and wellbeing of children [5], particularly given their cognitive and developmental vulnerabilities [6]. In recent years, there has been a substantial shift in children's media practices, from the dominance of television viewing to increasing time being spent online, including social media and content-sharing platforms (e.g., YouTube), subscription video on demand services (e.g., Netflix) and games (e.g., Fortnite) [7, 8]. Globally, one-third of internet users are children and they are online for an average of approximately $15 \mathrm{~h}$ per week, typically via portable

karger@karger.com

(C) 2020 S. Karger AG, Basel

www.karger.com/anm

Karger! devices such as tablets, laptops or smartphones [7, 8]. While this ubiquitous connectivity clearly provides opportunity for widespread engagement with positive campaigns to fight obesity [9], there is a need to better understand where children spend their digital time and what messages they are receiving about food and eating. Despite many social media platforms (such as Facebook) setting minimum age requirements of 13 years, evidence shows that many people younger than this have profiles and are active on these sites with or without their caregivers' knowledge and consent [8]. Where children have gone marketers have followed, and it is estimated that spend on digital marketing to children will reach USD 1.7 billion by 2021 [7]. The United States and China are the largest online advertising markets in the world, with the United Kingdom in the third place as the largest in Europe [10, 11].

Digital marketing, defined as "promotional activity, delivered through a digital medium, that seeks to maximise impact through creative and/or analytical methods" [5, p11] takes place in a complex ecosystem involving multiple actors including advertising technology ("adtech") companies, publishers and brands/agencies 
[12]. Marketing is largely delivered "programmatically" (i.e., automated buying and selling of targeted advertising impressions) [12]. It is driven by data analytics and powerful creative techniques, many of which are unique to the digital format (such as virtual environments and augmented realities) [5]. It has been estimated that by the age of 13 years, adtech companies have collected over 72 million data points on a child, equivalent to 12,000 pieces of data for each hour spent online [13]. Although this is almost certainly an underestimation given that this excludes the trackers used by Facebook, Twitter, and YouTube among others [13], this exemplifies the unique ability of digital marketing to be personalised and tailored to individuals, in a way that is likely to make the persuasive impact even greater than for generic campaigns [14].

In general, the role of screen time in driving obesity is well-known [15]. For television food advertising specifically, the extent of children's likely exposure [16], the marketing techniques used [17], the impact on eating behaviour [18] and the evidence for a causal relationship with body weight [19] are relatively well characterised. For digital marketing, this is not yet the case. There are some fundamental ethical and legal barriers that make characterising digital marketing prevalence and effects challenging for researchers [20], while the platforms retain the answers in-house with little scrutiny [5]. Nevertheless, there is emerging evidence to suggest that food marketing is highly prevalent in digital spaces where young people gather. One study of 10 websites popular with adolescents (12-17 years) in Canada found 14.4 million food advertisements in a single year, with cakes, cookies, and ice cream the most frequently advertised products [21]. Another study examining YouTube videos popular with children reported that foods and beverages were advertised more frequently than any other product ( $38 \%$ of ads) and a majority (56.3\%) promoted unhealthy foods [22]. One key feature of these studies is that they explore digital marketing to which children are likely to be exposed (by virtue of the popularity of the media with this age group) rather than what is "targeted" to children. As the impact of marketing on behaviour is a function of both exposure and power [23], it is typically more useful for researchers to use this approach rather than seeking to guess who the brands and marketers were hoping to reach.

Traditional advertising has tended to take a branding approach [24] and digital advertising appears to follow the same pattern [25]. Brand messaging is often deeply immersed in digital games, with contemporary advertis- ing techniques including pop-ups and "unlock to play" advertisements evident $[26,27]$. Brands can use digital media to cultivate more vibrant and interactive "brand personalities" in a way that was not possible with traditional media [28]. Digital marketers use tactics of peer engagement, emotion and entertainment to persuade young people to respond [29]. This appears critical to the effect [30]. Young people create posts on social media that replicate major food marketing campaigns [31] and this "earned media" can proliferate through social networks and across the digital sphere quickly and powerfully [28]. Similarly, brands are able to leverage the power of social media influencers to propagate their messages, and it appears to work. In a recent study, when children (911 years) were exposed to influencer marketing of unhealthy foods via YouTube, they consumed significantly more of the marketed snack relative to the alternative brand [32], demonstrating a brand-specific effect that was not tempered by the presence of a disclosure informing children that they were viewing marketing content. When the exposure was to influencer marketing via Instagram, a non-specific effect on intake was found whereby children consumed almost $100 \mathrm{kcal}$ more than the control group at a subsequent snack opportunity where the marketed foods were not available [33]. This is consistent with the beyond-brand consumption effects seen for television food advertising [34, 35].

Although still in relative infancy, there is sufficient evidence emerging to suggest that concern about the public health implications of young people's exposure to digital marketing for unhealthy foods and beverages is justified [36]. Where do researchers and policymakers go from here? Novel methodologies such as screen capture are showing promise for characterising marketing exposure through social media apps [37] and automated tools are under development that may support more widespread monitoring activity to generate evidence to inform policy developments in this area [12]. While effective regulation of the digital world is challenging and is yet to be achieved in any country [38], progress is being made to explore potential avenues for leverage [5] and provide a "best practice checklist" to inform government approaches [39]. There is progress shown by the introduction of the General Data Protection Regulations across the EU in 2018, and there are calls to update the Children's Online Privacy Protection Act in the US [40]. However, more must be done, and quickly, to ensure that young people can participate freely in the digital world, benefitting from the information age to the maximum degree, without their dietary health being adversely affected. 
Recommendations for Research and Further Action

We call for:

- Research to explore the impact of digital food and beverage marketing on normalisation of eating behaviours and longer-term effects on health outcomes in children (across childhood, from pre-schoolers to adolescents)

- Efforts to raise awareness of this issue among stakeholders including consumers (young people, parents), health campaigners and experts, and policymakers to encourage parental intervention and political will for action

- All relevant scientific societies dedicated to child health to work together to achieve meaningful policy progress to restrict children's exposure to marketing for unhealthy foods and beverages online

- Greater transparency from the food and beverage industries and the marketers with respect to the data they hold on digital food marketing prevalence and impact, and the facilitation of appropriate access for researchers to those data
- Governments to introduce or strengthen policies to restrict the exposure of young people (including adolescents) to the digital marketing of unhealthy foods and beverages.

\section{Disclosure Statement}

The authors declare that they have no conflicts of interest to disclose.

\section{Funding Sources}

No funding was received for this work.

\section{Author Contributions}

E.B. conceptualized the work, and led interpretation of literature and preparation of drafts. D.T., A.M., S.R.-D., M.-L.F., and D.W. made substantial contributions to the conception of the work and revised drafts critically for important intellectual content. All authors approved the final manuscript as submitted and agree to be accountable for all aspects of the work.

\section{References}

1 World Health Organization. (2016). Report of the Commission on Ending Childhood Obesity. WHO: Geneva, Switzerland. Available from: https://www.who.int/end-childhood-obesity/publications/echo-report/en/.

2 Brown T, Moore TH, Hooper L, Gao Y, Zayegh A, Ijaz S, et al. Interventions for preventing obesity in children. Cochrane Database Syst Rev. 2019 Jul;7:CD001871.

3 UK Government. 2019. Government response to the House of Commons Health and Social Care Select Committee report on Childhood obesity: Time for action, Eighth Report of Session 2017-19. Available from: https://www.parliament.uk/documents/ commons-committees/Health/Correspondence/2017-19/Childhood-obesity-Government-Response-to-eighth-report-17-19.pdf.

4 European Union. 2014. EU Action Plan on Childhood Obesity 2014-2020. Available from:http://publichealthwell.ie/node/748993.

5 WHO Regional Office for Europe. 2016. Tackling food marketing to children in a digital world: trans-disciplinary perspectives. Available from: http://www.euro.who.int/en/ health-topics/disease-prevention/nutrition/ publications/2016/tackling-food-marketingto-children-in-a-digital-world-trans-disciplinary-perspectives-2016.

6 Michel M, Beck D, Block N, Blumenfeld H, Brown R, Carmel D, et al. Opportunities and challenges for a maturing science of con- sciousness. Nat Hum Behav. 2019 Feb;3(2): 104-7.

7 PwC. 2019. Kids digital media report 2019. Commissioned by Superawesome. Available from: https://content.superawesome.com/ pwc-kids-digital-advertising-report-2019.

8 Ofcom. 2019. Children and parents: Media use and attitudes report 2018. Available from: https://www.ofcom.org.uk/research-and-da$\mathrm{ta} /$ media-literacy-research/childrens/children-and-parents-media-use-and-attitudesreport-2018.

9 Evans WD, Christoffel KK, Necheles JW, Becker AB. Social marketing as a childhood obesity prevention strategy. Obesity (Silver Spring). 2010 Feb;18(Suppl 1):S23-6.

10 UK Advertising Association. 2019. Advertising pays 7: UK advertising's digital revolution. Available from: https://www.adassoc.org.uk/ resource/uk-advertisings-digital-revolution/.

11 House of Lords. 2018. UK advertising in a digital age. Select Committee on Communications, 1st Report of Session 2017-19. Available from: https://publications.parliament.uk/pa/ ld201719/ldselect/ldcomuni/116/116.pdf.

12 WHO Regional Office for Europe. 2019. Monitoring and restricting digital marketing of unhealthy products to children and adolescents. Available from: http://www.euro. who.int/en/health-topics/disease-prevention/nutrition/publications/2019/monitoring-and-restricting-digital-marketing-of-un- healthy-products-to-children-and-adolescents-2019.

13 Superawesome. 2017. Blog: How much data do adtech companies collect on kids before they turn 13. Available from: https://blog.superawesome.tv/2017/12/13/how-much-datado-adtech-companies-collect-on-kids-before-they-turn-13/.

14 Matz SC, Kosinski M, Nave G, Stillwell DJ. Psychological targeting as an effective approach to digital mass persuasion. Proc Natl Acad Sci USA. 2017 Nov;114(48):12714-9.

15 Robinson TN, Banda JA, Hale L, Lu AS, Fleming-Milici F, Calvert SL, et al. Screen Media Exposure and Obesity in Children and Adolescents. Pediatrics. 2017 Nov; 140 Suppl 2:S97-101

16 Kelly B, Vandevijvere S, Ng S, Adams J, Allemandi L, Bahena-Espina L, et al. Global benchmarking of children's exposure to television advertising of unhealthy foods and beverages across 22 countries. Obesity Reviews. Available from: https://doi.org/https:// doi.org/10.1111/obr.12840.; part of the upcoming supplement 'Future Directions on Obesity Prevention' by the Lancet Commission on Obesity, 2019.

17 Jenkin G, Madhvani N, Signal L, Bowers S. A systematic review of persuasive marketing techniques to promote food to children on television. Obes Rev. 2014 Apr;15(4):28193. 
18 Boyland EJ, Nolan S, Kelly B, Tudur-Smith C, Jones A, Halford JC, et al. Advertising as a cue to consume: a systematic review and metaanalysis of the effects of acute exposure to unhealthy food and nonalcoholic beverage advertising on intake in children and adults. Am J Clin Nutr. 2016 Feb;103(2):519-33.

19 Norman JA, Kelly B, Boyland E, McMahon AT. The impact of marketing and advertising on food behaviours: evaluating the evidence for a causal relationship. Curr Nutr Rep. 2016; 5(3):139-49.

20 Tatlow-Golden M, Verdoodt V, Oates J, Jewell J, Breda JJ, Boyland E, et al. A safe glimpse within the "black box"? Ethical and legal principles when assessing digital marketing of food and drink to children. WHO Public Health Panorama. 2017;3(4):613-21.

21 Potvin Kent M, Pauzé E. The Frequency and Healthfulness of Food and Beverages Advertised on Adolescents' Preferred Web Sites in Canada. J Adolesc Health. 2018 Jul;63(1): 102-7.

22 Tan L, Ng SH, Omar A, Karupaiah T. What's on YouTube? A Case Study on Food and Beverage Advertising in Videos Targeted at Children on Social Media. Child Obes. 2018 Jul; 14(5):280-90.

23 WHO. Set of recommendations on the marketing of food and non-alcoholic beverages to children. WHO Geneva; 2010. pp. 4-5.

24 Connor SM. Food-related advertising on preschool television: building brand recognition in young viewers. Pediatrics. 2006 Oct; 118(4): 1478-85.

25 Vassallo AJ, Kelly B, Zhang L, Wang Z, Young S, Freeman B. Junk Food Marketing on Instagram: content Analysis. JMIR Public Health Surveill. 2018 Jun;4(2):e54.
26 Smith R, Kelly B, Yeatman H, Boyland E. Food Marketing Influences Children's Attitudes, Preferences and Consumption: A Systematic Critical Review. Nutrients. 2019 Apr; 11(4):875

27 Meyer M, Adkins V, Yuan N, Weeks HM, Chang YJ, Radesky J. Advertising in Young Children's Apps: A Content Analysis. J Dev Behav Pediatr. 2019 Jan;40(1):32-9.

28 Coolr. 2019. Burger King win at PRCA Digital Awards. Available from: https://www. wearecoolr.com/coolr-and-burger-kingwin-at-prca-digital-awards/.

29 Boyland E, Tatlow-Golden M. Exposure, Power and Impact of Food Marketing on Children: Evidence Supports Strong Restrictions. Eur J Risk Regul. 2017;8(2):224-36.

30 Baldwin HJ, Freeman B, Kelly B. Like and share: associations between social media engagement and dietary choices in children. Public Health Nutr. 2018 Dec;21(17):3210_ 5

31 Holmberg C, E Chaplin J, Hillman T, Berg C. Adolescents' presentation of food in social media: an explorative study. Appetite. 2016 Apr;99:121-9.

32 Coates AE, Hardman CA, Halford JC, Christiansen P, Boyland EJ. The effect of influencer marketing of food and a "protective" advertising disclosure on children's food intake. Pediatr Obes. 2019 Oct;14(10):e12540.

33 Coates AE, Hardman CA, Halford JC, Christiansen P, Boyland EJ. Social Media Influencer Marketing and Children's Food Intake: A Randomized Trial. Pediatrics. 2019 Apr;143(4):e20182554.

34 Halford JC, Boyland EJ, Hughes GM, Stacey L, McKean S, Dovey TM. Beyond-brand effect of television food advertisements on food choice in children: the effects of weight status. Public Health Nutr. 2008 Sep;11(9):897904

35 Cairns G, Angus K, Hastings G, Caraher M. Systematic reviews of the evidence on the nature, extent and effects of food marketing to children. A retrospective summary. Appetite. 2013 Mar;62:209-15.

36 Buchanan L, Kelly B, Yeatman H, Kariippanon K. The Effects of Digital Marketing of Unhealthy Commodities on Young People: A Systematic Review. Nutrients. 2018 Jan;10(2): 148

37 Potvin Kent M, Pauzé E, Roy EA, de Billy N, Czoli C. Children and adolescents' exposure to food and beverage marketing in social media apps. Pediatr Obes. 2019 Jun;14(6):e12508.

38 World Health Organization. Evaluating implementation of the WHO Set of Recommendations on the marketing of foods and nonalcoholic beverages to children: Progress, challenges and guidance for next steps in the WHO European Region. WHO Europe: Copenhagen, Denmark, 2018. Available from: http://www.euro.who.int/__data/assets/pdf_ file/0003/384015/food-marketing-kids-eng. pdf.

39 Critchlow N, Angus K, Stead M, Newberry La Vey J, Whiteside E, Clarke M, et al. Digital Feast: Navigating a digital marketing mix, and the impact on children and young people's dietary attitudes and behaviours. Available from: https://www.cancerresearchuk. org/sites/default/files/cancer-stats/digital_ feast_june_2019_-_full_report/digital_ feast_june_2019_-_full_report.pdf. 2019.

40 Chester J. 2019. Time to legislate COPPA 2.0. Available from: https://www.democraticmedia.org/article/time-legislate-coppa-20. 